\title{
Evaluate the Cooling Performance of Transmit/Receive Module Cooling System in Active Electronically Scanned Array Radar
}

\author{
Jun Su Park $1, * \mathbb{C}$, Dong-Jun Shin ${ }^{2}$, Sung-Hwan Yim ${ }^{2}$ and Sang-Hyun Kim ${ }^{2}$ \\ 1 Department of Automotive Engineering, Korea National University of Transportation, Chungju 27469, Korea \\ 2 LIG Nex1 Corporation, Seongnam 13488, Korea; dongjun.shin@lignex1.com (D.-J.S.); \\ shyim1031@lignex1.com (S.-H.Y.); kimsh1207@lignex1.com (S.-H.K.) \\ * Correspondence: js_park@ut.ac.kr
}

Citation: Park, J.S.; Shin, D.-J.; Yim, S.-H.; Kim, S.-H. Evaluate the Cooling Performance of Transmit/Receive Module Cooling System in Active Electronically Scanned Array Radar. Electronics 2021, 10, 1044.

https://doi.org/10.3390/

electronics10091044

Academic Editor: Massimo Donelli

Received: 6 April 2021

Accepted: 26 April 2021

Published: 28 April 2021

Publisher's Note: MDPI stays neutral with regard to jurisdictional claims in published maps and institutional affiliations.

Copyright: (c) 2021 by the authors. Licensee MDPI, Basel, Switzerland. This article is an open access article distributed under the terms and conditions of the Creative Commons Attribution (CC BY) license (https:/ / creativecommons.org/licenses/by/ $4.0 /)$.

\begin{abstract}
The active electronically scanned array (AESA) radar consists of many transmit/receive $(\mathrm{T} / \mathrm{R})$ modules and is used to track missiles approaching destroyers and fighters. The performance of the AESA radar depends on the $\mathrm{T} / \mathrm{R}$ module temperature. The $\mathrm{T} / \mathrm{R}$ module temperature should be maintained under $80^{\circ} \mathrm{C}$ to guarantee the performance of the AESA radar. In order to match the design requirements of the cooling system of the AESA radar, it is necessary to evaluate the cooling performance according to various operation/installation environments. In this study, computational fluid analysis was performed by changing the number of $\mathrm{T} / \mathrm{R}$ modules and the coolant mass flow rate to evaluate the cooling performance of the AESA radar coolant channel. The number of T/R modules was changed from 2 to 16, and the number of coolant inlet Re was changed from 277 to 11,116. As a result, it was confirmed that the temperature increased as the number of $\mathrm{T} / \mathrm{R}$ modules increased. In addition, when the coolant status was laminar flow, it was confirmed that the cooling performance was significantly lowered. Therefore, the coolant status should be transient or turbulence to decrease the temperature of the T/R module. Additionally, the correlation between the arrangement of the $\mathrm{T} / \mathrm{R}$ module and the cooling flow must be considered to cool the AESA radar.
\end{abstract}

Keywords: active electronically scanned array (AESA) radar; transmit/receive (T/R) module; highpower amplifier (HPA); cooling performance; conjugate heat transfer; Rayleigh number

\section{Introduction}

The active electronically scanned array (AESA) radar is used in fire control systems to track and intercept missiles because it can rapidly detect multiple high-resolution electromagnetic wave beams in a specific space using electronic circuits and neutralize the target signals. Owing to these properties, AESA radars are applied to fighters to perform various functions, including the detection and tracking of aircraft and missiles, fire control, and guided weapon control. It is also installed in the close-in weapon system (CIWS) on a destroyer and is used for detecting and destroying approaching enemy aircraft or anti-ship missiles.

An AESA radar is composed of many transmit/receive (T/R) modules, and a phased array radar beam consists of the sum of the $T / R$ module outputs [1-3]. Because beam scanning is performed by adjusting the phase and size of each module, $T / R$ modules with high outputs are required. In addition, the detection performance of the AESA radar can be improved only if the radar is composed of multiple T/R modules. Accordingly, the AESA radar is generally constructed from hundreds to thousands of $T / R$ modules to ensure proper operation.

The main components of a $\mathrm{T} / \mathrm{R}$ module installed in an AESA radar are: high-power amplifier (HPA), circulator, and phase shifter. Each semiconductor device not only has functions for receiving and transmitting RF signals, but is also equipped with a power amplifier and a phase shifter mounted on the T/R module, which greatly increases the heat locally generated by semiconductor devices. The output of the AESA radar varies greatly 
depending on the temperature of the T/R module; in particular, it reduces sharply at temperatures exceeding $80^{\circ} \mathrm{C}$ [4]. To prevent the $\mathrm{T} / \mathrm{R}$ module temperature from increasing, each device that generates a high-power output is constructed from materials with high thermal conductivity for efficient heat transfer; alternatively, a coolant channel is installed to pass through the $\mathrm{T} / \mathrm{R}$ module to cool it down [5-7]. With the increasing demand for high-performance AESA radars, the coolant channel layout for controlling the temperatures of the hundreds to thousands of $\mathrm{T} / \mathrm{R}$ modules constituting an AESA radar has become an important parameter.

In recent years, the maximum heat flux in the T/R module is close to $50 \mathrm{~W} / \mathrm{cm}^{2}$ with the increasing output and number of $\mathrm{T} / \mathrm{R}$ modules. Therefore, the liquid cooling has been required to apply to AESA radar cooling to maintain the maximum temperature under $80{ }^{\circ} \mathrm{C}$ in the $\mathrm{T} / \mathrm{R}$ module. The selection of liquid cooling can be regarded as an appropriate method considering the reference [8]. The liquid cooling system necessitates installing large-capacity coolant circulation and heat exchange systems [9]. However, given the spatial constraints of the structural framework of a fighter or destroyer, the design of a cooling system is focused on improving the cooling performance of coolant channels and reducing the coolant mass flow [10].

Because the limited space on a fighter does not allow the installation of a bulky heat exchanger or coolant circulator, the optimal design of the coolant channel is crucial. In contrast, the size of a coolant circulator or heat exchanger is not an important factor for the CIWS on a destroyer owing to the relatively large inner space of the destroyer. In recent years, however, the space requirements of the coolant circulator have substantially increased for providing sufficient coolants, because the output and integration rate of $T / R$ modules in AESA radars have been enhanced. Furthermore, the AESA radar system in the destroyer is composed of quad-face detection and single-face tracking radars with greatly increased output to track anti-ship missiles approaching the destroyer with $360^{\circ}$ scan coverage. Hence, the mass flow rate of coolant and the pressure drop in the coolant supply circuit is significantly increased in comparison with that in the fighter. Accordingly, considerable importance is assigned not only to the size of the coolant circulator and heat exchanger but also to the level of internal pressure drop, which should be reflected in the coolant channel design.

The purpose of this study was to obtain basic data for designing the coolant channel for an AESA radar system applicable to the CIWS on a destroyer. In order to maintain the maximum temperature of the AESA radar below the design value and to determine the coolant mass flow rate for operation, cooling performance data under various design and operating conditions is required. To establish the related database, we assessed the cooling performance in relation to the number of $\mathrm{T} / \mathrm{R}$ modules installed in an AESA radar using computational fluid dynamics (CFD) analysis. The results obtained from this study are expected to provide useful data for a basic design of AESA radar, including the arrays of hundreds to thousands of $T / R$ modules.

\section{Materials and Methods}

\subsection{Research Subject and Model}

The subject of this study was the T/R module to be installed in the CIWS detection and tracking radar. The $T / R$ module included four channels, each of which consisted of a circulator, an HPA, a core chip, two low-noise amplifiers (LNA1 and LNA2), and a digital radar array (DRA), as illustrated in Figure 1. Devices necessary to prepare four such T/R channels were mounted on a printed circuit board (PCB) which was fixed in an aluminum housing. With one aluminum housing accommodating two PCB substrates on the left and right sides, one $\mathrm{T} / \mathrm{R}$ module consisted of eight $\mathrm{T} / \mathrm{R}$ channels and the aluminum housing. 


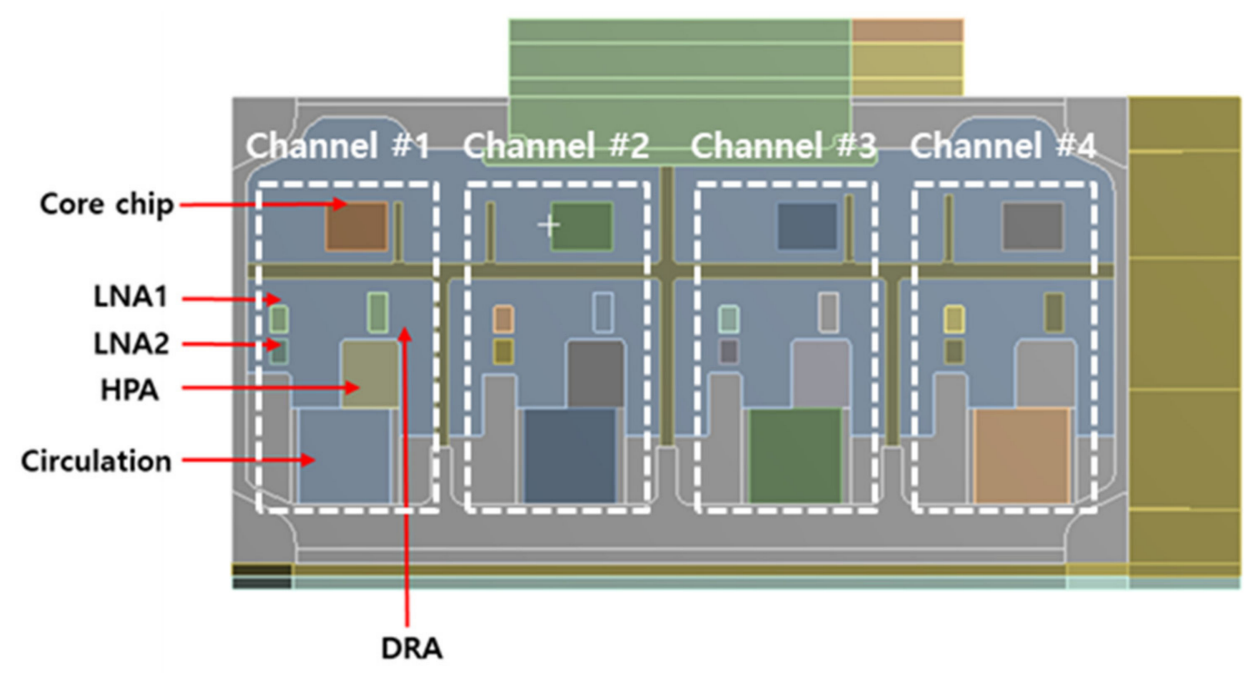

Figure 1. Device configuration and layout inside the transmit/receive $(T / R)$ module.

Table 1 outlines the thermal conditions of each of the devices inside a T/R module. Among the devices comprising the T/R module, HPA has the highest rate of heat $(6.58 \mathrm{~W})$. When predicting the $\mathrm{T} / \mathrm{R}$ module temperature, prediction accuracy primarily depends on the accuracy of the prediction model analysis, considering not only the thermal conditions of each device but also the installation configuration of the devices and the contacts between them. Regarding the device contact surface, the core chip and LNA 1 were installed directly on the aluminum housing and the heat generated by them was supposed to be directly transferred to the housing. In the case of the HPA, a thin CuW layer was between the device and the housing, which was reflected in the analysis by considering the contact resistance. Thus, the installation conditions were reflected in thermal analysis. For the circulator, LNA 2, and DRA, which were installed on the PCB, care was taken to simulate the thermal conduction that actually occurs during the production as accurately as possible by modeling copper via shape. Among the semiconductor device materials, $\mathrm{Si}$ was selected as the material for each electronic device, and its physical properties were entered as input variables. For the PCB substrate, the material properties of FR4 were applied.

Table 1. Thermal and contact information of each device.

\begin{tabular}{ccccc}
\hline Device Name & $Q$ & Size $(\mathbf{m m})$ & $\dot{Q}$ & Device Contact Surface \\
\hline Circulator & 0.47 & $7.0 \times 7.0$ & 9592 & Housing \\
Core chip & 0.42 & $3.6 \times 4.7$ & 24,823 & Housing \\
DRA (Digital radar array) & 0.33 & $2.9 \times 1.4$ & 81,281 & PCB (Printed circuit board) \\
HPA (High-power amplifier) & 6.58 & $5.0 \times 2.8$ & 470,000 & CuW \\
LNA 1 (Low-noise amplifier) & 0.22 & $1.9 \times 1.3$ & 89,069 & Housing \\
LNA 2 (Low-noise amplifier) & 0.22 & $1.9 \times 1.3$ & 89,069 & PCB \\
\hline
\end{tabular}

The cooling plate along which the coolant channel runs was also made of aluminum and was located at the bottom of the aluminum housing accommodating the $\mathrm{T} / \mathrm{R}$ module. Because this study aimed to obtain basic data for cooling design, the cooling performance was evaluated by designing the interior of the coolant channel with a smooth square channel. Future research is supposed to apply various cooling methods, such as corrugation and collision jet, depending on the results of cooling performance. The size of the inlet of the coolant channel was set at $7 \mathrm{~mm} \times 7 \mathrm{~mm}$, and EGW 55 was used as the coolant. The physical properties of EGW 55 and each material are presented in Table 2. 
Table 2. Physical properties of the components and coolant.

\begin{tabular}{|c|c|c|c|c|c|}
\hline Component & Material & $\begin{array}{l}\text { Density } \\
\left(\mathrm{kg} / \mathrm{m}^{3}\right)\end{array}$ & $\begin{array}{l}\text { Specific Heat } \\
(\mathrm{J} /(\mathrm{kg} \cdot \mathrm{K}))\end{array}$ & $\begin{array}{l}\text { Conductivity } \\
(\mathrm{W} /(\mathrm{m} \cdot \mathrm{K}))\end{array}$ & $\begin{array}{r}\text { Viscosity } \\
(\mathrm{kg} /(\mathrm{m} \cdot \mathrm{s}))\end{array}$ \\
\hline Housing & Aluminum & 2700 & 896 & 167 & \\
\hline PCB & FR4 & 1900 & 600 & 0.2 & \\
\hline Electronic device & SIC & 3210 & 750 & 120 & \\
\hline Coolant & EGW55 at $25^{\circ} \mathrm{C}$ & 1070 & 3204 & 0.4016 & 0.00385 \\
\hline$(\operatorname{Pr}=29.85)$ & EGW55 at $30^{\circ} \mathrm{C}$ & 1067 & 3235 & 0.4012 & 0.00331 \\
\hline
\end{tabular}

As illustrated in Figure 2, eight-channel T/R modules were modeled in series and the temperature inside the $\mathrm{T} / \mathrm{R}$ module during a radar operation was predicted after installing 2-16 T/R modules in series on a coolant channel, as shown in Figure 2.

(a)

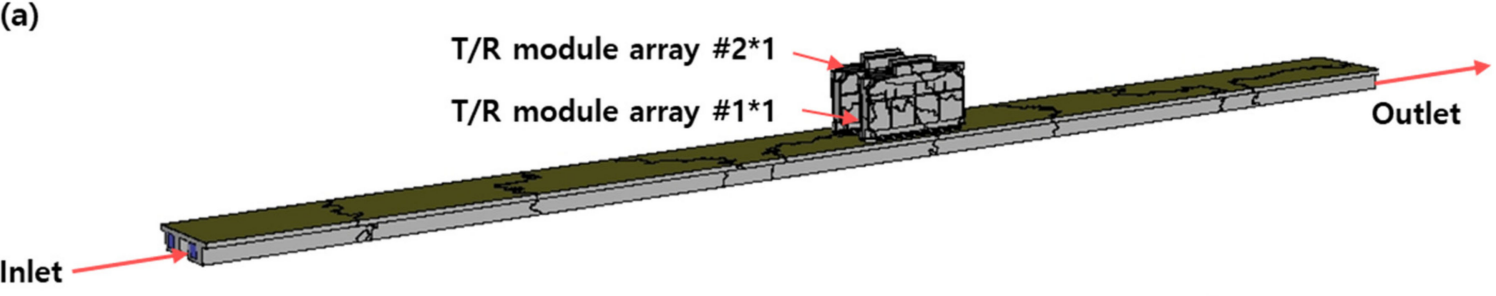

Inlet

(b)

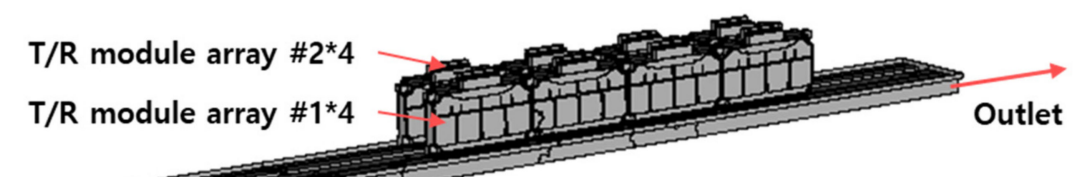

(c)

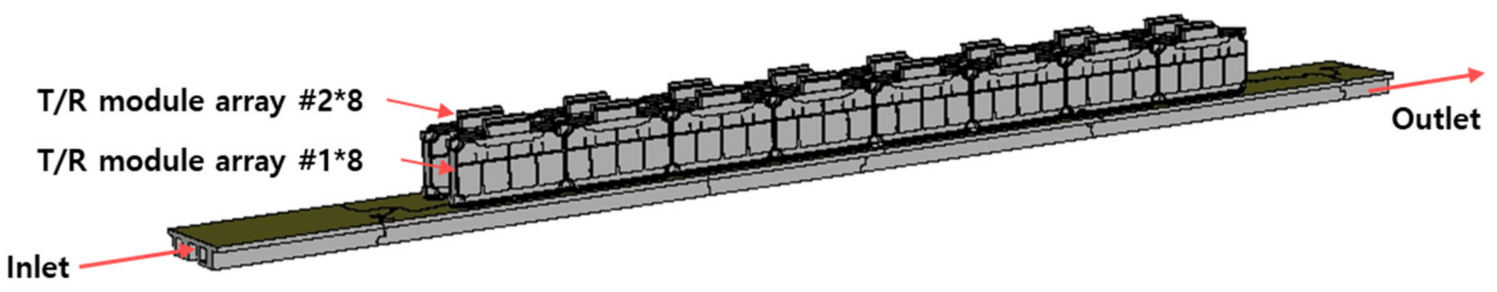

Figure 2. $\mathrm{T} / \mathrm{R}$ module arrays modeling; (a) two $\mathrm{T} / \mathrm{R}$ modules, (b) eight $\mathrm{T} / \mathrm{R}$ modules, (c) $16 \mathrm{~T} / \mathrm{R}$ modules.

\subsection{Methods}

For the prediction of the $\mathrm{T} / \mathrm{R}$ module temperature, CFD modeling was performed for the T/R devices, housing, and coolant channel using Ansys Fluent v.19.5 for calculation. In this conjugate heat transfer calculation, the flow analysis area included solely the flow field of the cooling water within the coolant channel, and the remaining area was calculated by inputting the wall convective heat transfer and heat generation conditions. Therefore, the grid was generated by applying inflation to calculate the wall boundary layer inside the coolant channel. As illustrated in Figure 3, given the extremely small sizes of the devices inside the module and the large aspect ratio, structured grid mesh was generated and applied to all cases. 


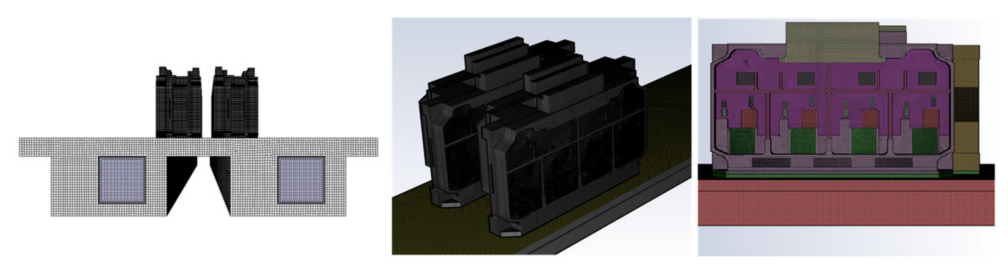

Figure 3. Two-T/R module array grid configurations.

The mesh sensitivity test (Figure 4) was performed to change the number of the mesh of one $\mathrm{T} / \mathrm{R}$ module model at $\mathrm{Re}=277$. The outlet temperature of the coolant channel was converged when the number of the grid was $12,862,580$. The convergence time was approximately $10 \mathrm{~h}$ using the 8-core CPU and $64 \mathrm{~GB}$ ram, and the iteration number of convergence was approximately 1000. Based on the mesh sensitivity test results, the number of the grid was decided and the number of grid points were $12,862,580$ for one $\mathrm{T} / \mathrm{R}$ module, 22,756,940 for two T/R modules, and 35,940,420 for eight $\mathrm{T} / \mathrm{R}$ modules.

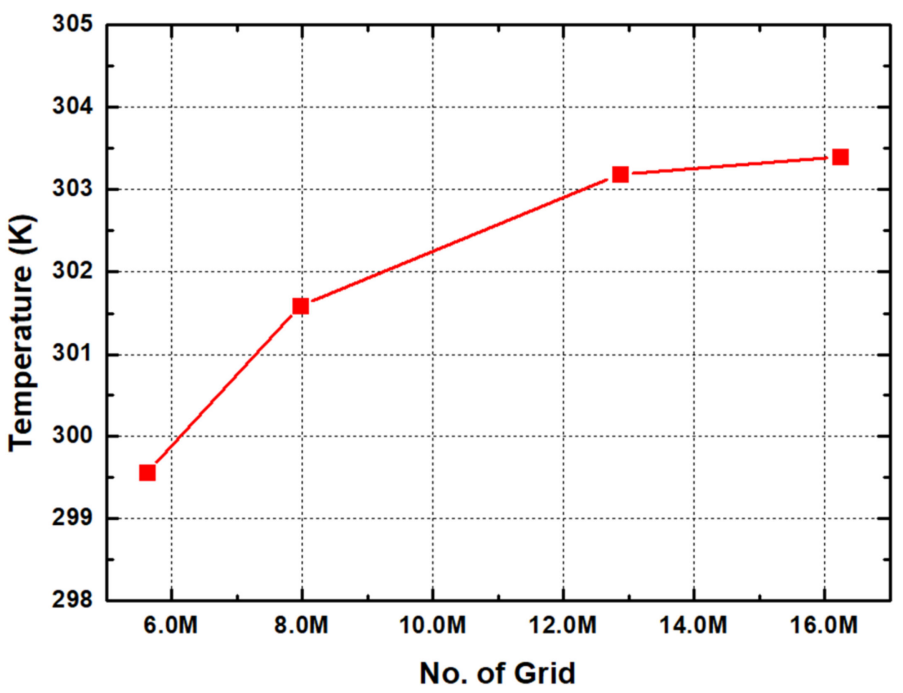

Figure 4. Mesh sensitivity test results.

The thermal conditions and material properties of each $T / R$ device were entered as the boundary conditions as presented above. The CFD was performed by modifying the Reynolds number at the coolant channel inlet from 277.9 to $11,116.9$. The coolant flow rate at the inlet was altered from 0.125 to $5.0 \mathrm{~m} / \mathrm{s}$, and the temperature was set to $25^{\circ} \mathrm{C}$. The inlet flow path of 10 times the channel hydraulic diameter was modeled to make the fully developed flow in the T/R module location. The laminar condition and the SST k- $\omega$ model were adopted according to laminar flow $(\operatorname{Re}<2000)$ and turbulence flow $(\operatorname{Re}>2000)$ in inlet condition. The coolant inlet condition is determined in principle by the pressure drop of the entire system and the specifications of the coolant circulator. In this study, analysis was performed in a wide range of inlet boundary conditions to obtain basic data.

To verify the numerical analysis in this study, the Nusselt number on the coolant channel was compared with calculation results reference values [11]. The Nusselt number in the laminar flow is suggested to be a constant value in the constant heat flux wall condition by the reference. However, this study did not give the wall boundary conditions because it performed conjugate heat transfer analysis. Accordingly, heat was transferred from the $\mathrm{T} / \mathrm{R}$ module to the coolant, and the transferred heat flux varied depending on the location of the T/R module. The heat flux of coolant channel wall was a result of the conjugate heat transfer calculation. Hence, the wall of coolant channel did not match the constant heat flux wall condition. Therefore, the Nusselt number in this study calculation was a little different from the reference value. Nevertheless, overall the Nusselt number within the smooth coolant channel, according to the change of the inlet Reynolds number, 
was verified to agree with that on the wall, which was obtained from the analysis. The inlet flow conditions and Nusselt number are summarized in Table 3.

Table 3. Inlet flow conditions.

\begin{tabular}{ccccc}
\hline \multirow{2}{*}{$\begin{array}{c}\text { Inlet Flow } \\
(\mathbf{m} / \mathbf{s})\end{array}$} & Mass Flow & Reynolds No. & \multicolumn{2}{c}{ Nu-Verified Results } \\
\cline { 4 - 5 } & Rate $(\mathbf{k g} / \mathbf{s})$ & $\mathbf{R e})$ & Calculation & Reference [11] \\
\hline 0.125 & 0.00856 & 277.92 & 4.78 & $3.61\left(\dot{q}_{s}=\right.$ Const. $)$ \\
0.5 & 0.03424 & 1111.69 & 6.63 & $3.61\left(\dot{q}_{s}=\right.$ Const. $)$ \\
1 & 0.06848 & 2223.38 & 44.63 & Transient \\
5 & 0.3424 & $11,116.88$ & 152.26 & $154.34\left(\mathrm{Nu}=0.023 \operatorname{Re}^{0.8} \operatorname{Pr}^{0.4}\right)$ \\
\hline
\end{tabular}

The conjugate heat transfer of $\mathrm{T} / \mathrm{R}$ module cooling is calculated from the heat generation of each device to the convective cooling on the cooling plate by the coolant. Hence, the walls which are exposed to the ambient air must be regarded as the boundary conditions to calculate conjugate heat transfer. Because the AESA radar carrying the T/R modules is exposed to the ambient air and must be operated even under extreme conditions, it is thoroughly waterproofed; thus, the $\mathrm{T} / \mathrm{R}$ modules are exposed solely to the internal airflow without contact with the ambient air. Based on the internal convection resulting from the heat generation of the $T / R$ devices, the convective heat transfer coefficient on the $T / R$ device and PCB surfaces can be estimated by assuming the T/R module as a flat plate and calculating the Rayleigh number $(R a)$.

$$
R a_{L}=\frac{g \beta\left(T_{s}-T_{\infty}\right) L^{3} \cdot P r}{v^{2}}
$$

where $g$ is the gravitational acceleration, $\beta$ is the thermal expansion coefficient of air, $v$ is the coefficient of kinematic viscosity of air, $L$ is the length of the T/R device $(2-7 \mathrm{~mm})$, and Pr is the Prandtl number of air. The Ra of the T/R device was calculated under the following temperature conditions: surface temperature $T_{S}=70{ }^{\circ} \mathrm{C}$ (the limit temperature of the $\mathrm{T} / \mathrm{R}$ device) and ambient temperature $T_{\infty}=28^{\circ} \mathrm{C}$. The values used in calculation are presented in Table 4.

Table 4. Physical properties of air for Rayleigh number ( $\mathrm{Ra})$ calculation.

\begin{tabular}{|c|c|c|c|}
\hline Ambient Temperature $\left(T_{\infty}\right)$ & $28^{\circ} \mathrm{C}$ & Prandtl Number $(\mathrm{Pr})$ & 0.73 \\
\hline Surface Temperature $\left(T_{s}\right)$ & $70^{\circ} \mathrm{C}$ & $\begin{array}{c}\text { Coefficient of Kinematic } \\
\text { Viscosity }(v)\end{array}$ & $0.0000175\left(\mathrm{~m}^{2} / \mathrm{s}\right)$ \\
\hline Thermal Expansion Coefficient $(\beta)$ & $0.003671 / \mathrm{deg}$ & $L(\mathrm{~mm})$ & $1.9-7.0$ \\
\hline Rayleigh Number $(R a)$ & \multicolumn{3}{|c|}{$32.58(L=1.9 \mathrm{~mm})$ to $1629.17(L=7.0 \mathrm{~mm})$} \\
\hline
\end{tabular}

In general, the Ra values equal to or higher than 1760 are associated with natural convection; however, for Ra values lower than 1760, the surface convective heat transfer coefficient is known to be the same as the thermal conductivity of fluid. Because the Ra in the $\mathrm{T} / \mathrm{R}$ module ranges from 32.58 to 1629.17 (depending on the device length), which is lower than the reference value, $0.02461 \mathrm{~W} /(\mathrm{m} \cdot \mathrm{K})$, which is the thermal conductivity value of air, it was used as the wall boundary condition in lieu of the convective heat transfer coefficient at all the external surfaces of T/R devices and PCB surfaces. Ra was calculated on the $\mathrm{T} / \mathrm{R}$ devices with high temperature gaps between surface and ambient air due to heat generation, with the Ra on the PCB and aluminum housing converging toward zero owing to the quasi-absence of a temperature gap between surface and ambient air. Therefore, similar to the $T / R$ devices, the thermal conductivity value of air, $0.02461 \mathrm{~W} /(\mathrm{m} \cdot \mathrm{K})$, was used for the heat transfer coefficient to the wall conditions for the $T / R$ module cover and aluminum housing outer and inner walls showing in Figure 5. All boundary conditions in this study are summarized in Table 5. 

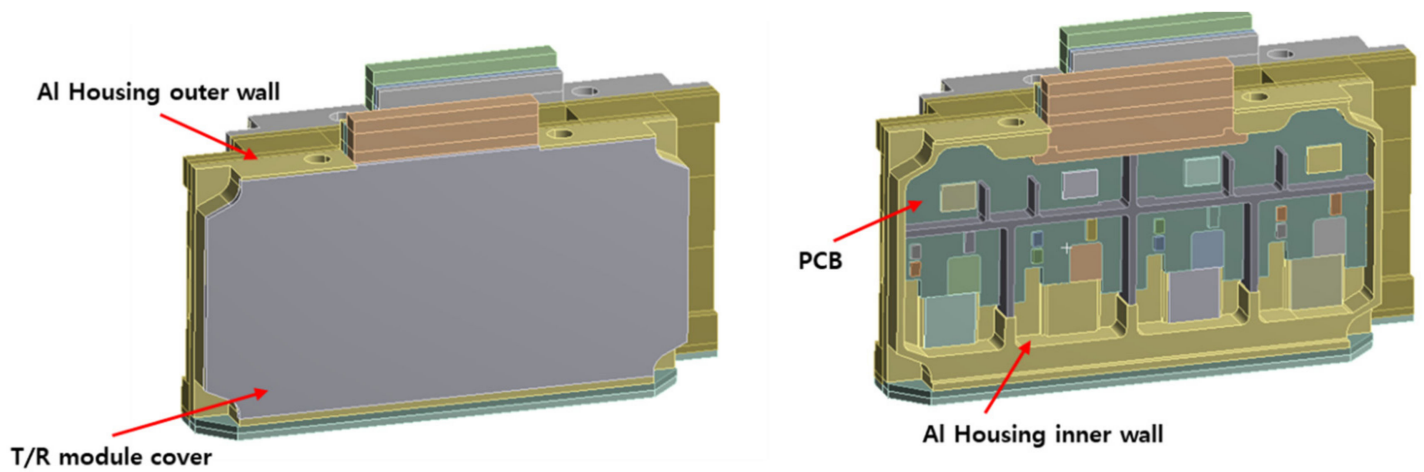

Figure 5. Surfaces to apply the convection heat transfer for boundary condition.

Table 5. Boundary conditions of calculation.

\begin{tabular}{cccc}
\hline Velocity Inlet & 0.125 to $5 \mathrm{~m} / \mathrm{s}$ & Coolant Inlet Temp. & $25^{\circ} \mathrm{C}$ \\
Pressure Outlet & $0 \mathrm{~Pa}$ & Ambient Temp. & $28{ }^{\circ} \mathrm{C}$ \\
Circulator & $9592 \mathrm{~W} / \mathrm{m}^{2}$ & HPA & $470,000 \mathrm{~W} / \mathrm{m}^{2}$ \\
Core Chip & $24,823 \mathrm{~W} / \mathrm{m}^{2}$ & LNA 1 & $89,069 \mathrm{~W} / \mathrm{m}^{2}$ \\
DRA & $81,281 \mathrm{~W} / \mathrm{m}^{2}$ & LNA 2 & $89,069 \mathrm{~W} / \mathrm{m}^{2}$ \\
Other Walls & & $0.02461 \mathrm{~W} /(\mathrm{m} \cdot \mathrm{K})$, and $28^{\circ} \mathrm{C}$ \\
\hline
\end{tabular}

\section{Results}

Figures 6 and 7 and Table 6 present the T/R module temperature distributions determined by the conjugate heat transfer analysis. The peak temperature of each $\mathrm{T} / \mathrm{R}$ module decreased as the coolant flow rate increased. As shown in Figure 4, as the coolant flow rate increases, the convective heat transfer coefficient of the interior surface of the coolant channel wall increases, which, in turn, raises the amount of heat released from the interior of the $\mathrm{T} / \mathrm{R}$ module to the outside, thereby resulting in a temperature drop.

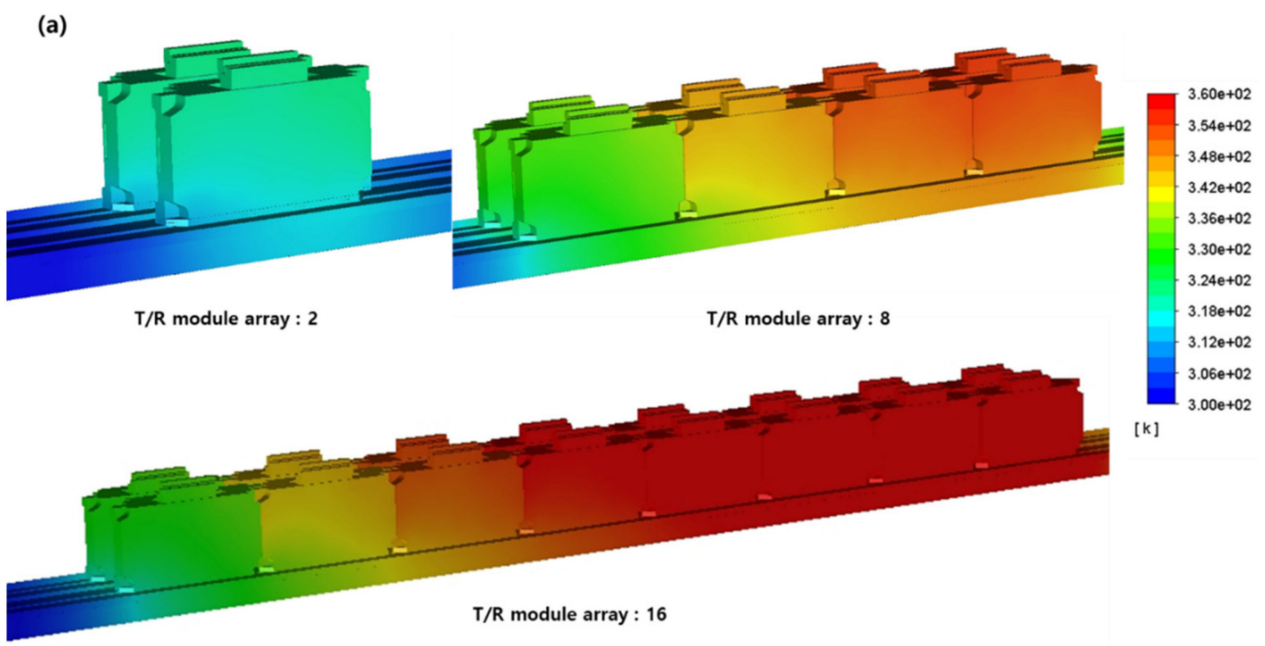

Figure 6. Cont. 

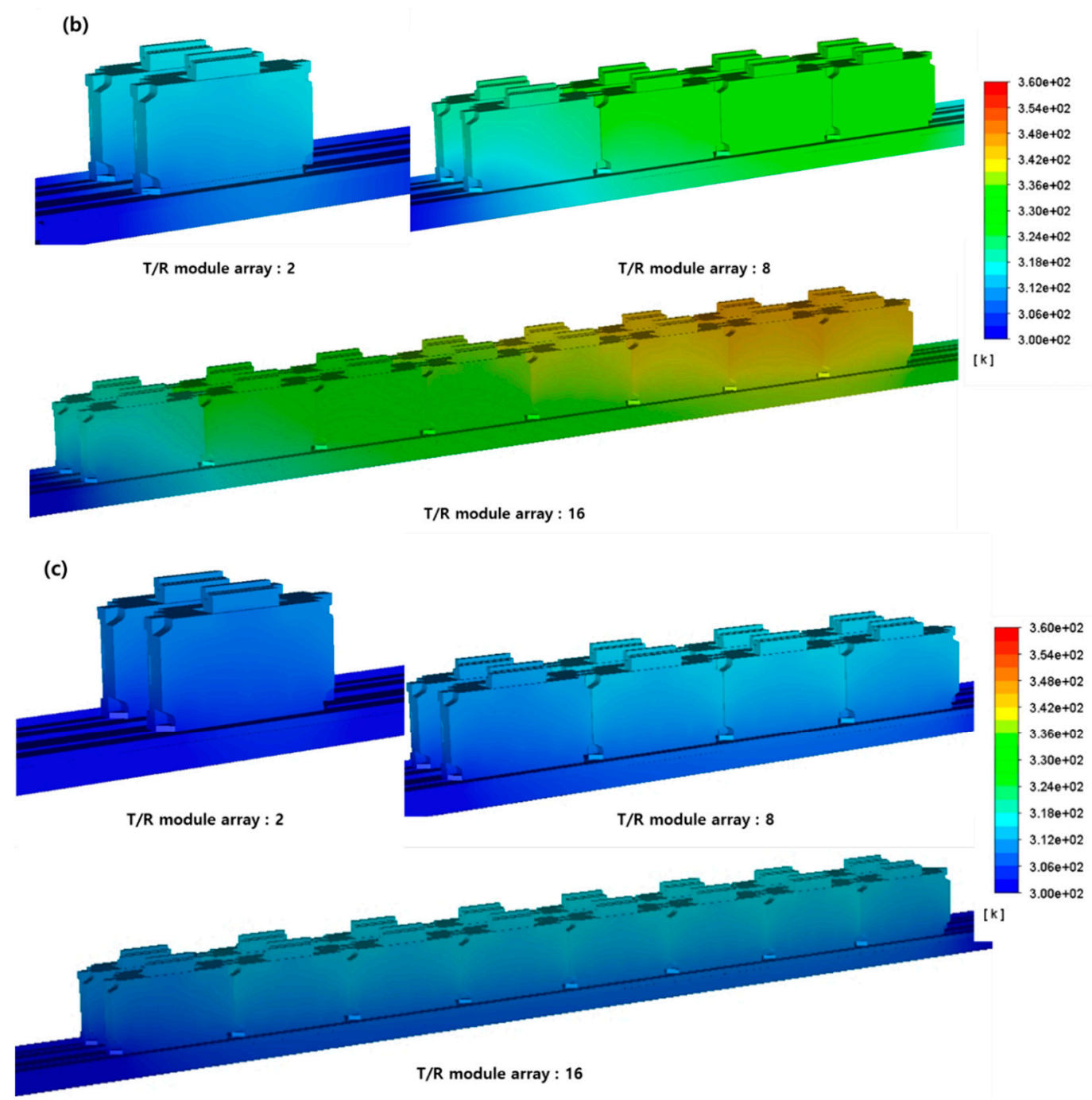

Figure 6. Ambient temperature distributions for each $T / R$ module array: (a) $V=0.125 \mathrm{~m} / \mathrm{s},(\mathbf{b}) \mathrm{V}=0.5 \mathrm{~m} / \mathrm{s},(\mathbf{c}) \mathrm{V}=1.0 \mathrm{~m} / \mathrm{s}$.

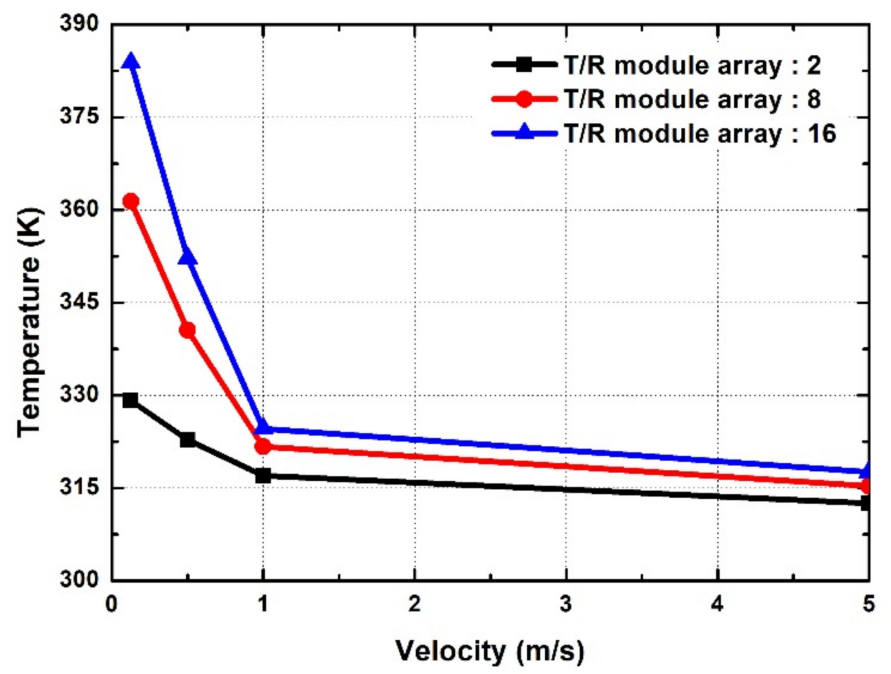

Figure 7. Peak DRA temperatures varying according to the number of $\mathrm{T} / \mathrm{R}$ modules and inlet condition. 
Table 6. Peak temperature (K) of each device depending on the operation conditions.

\begin{tabular}{|c|c|c|c|c|c|c|c|c|c|c|c|c|}
\hline \multirow{2}{*}{ Name } & \multicolumn{4}{|c|}{ Number of T/R Modules: 2} & \multicolumn{4}{|c|}{ Number of T/R Modules: 8} & \multicolumn{4}{|c|}{ Number of T/R Modules: 16} \\
\hline & 0.125 & 0.5 & 1 & 5 & 0.125 & 0.5 & 1 & 5 & 0.125 & 0.5 & 1 & 5 \\
\hline Circulator & 324.7 & 318.4 & 312.5 & 308.0 & 357.0 & 336.1 & 317.2 & 310.8 & 379.5 & 347.7 & 320.1 & 313.1 \\
\hline Core chip & 325.2 & 318.9 & 313.1 & 308.7 & 357.5 & 336.7 & 317.9 & 311.5 & 379.9 & 348.4 & 320.8 & 313.8 \\
\hline DRA & 329.1 & 322.8 & 317.0 & 312.5 & 361.4 & 340.6 & 321.7 & 315.3 & 383.8 & 352.2 & 324.6 & 317.6 \\
\hline HPA & 327.1 & 320.9 & 315.0 & 310.5 & 359.5 & 338.6 & 319.7 & 313.3 & 381.8 & 350.2 & 322.6 & 315.5 \\
\hline LNA 1 & 325.6 & 319.3 & 313.5 & 309.1 & 357.9 & 336.8 & 318.3 & 311.9 & 380.3 & 348.7 & 321.2 & 314.1 \\
\hline LNA 2 & 327.2 & 320.9 & 315.2 & 310.8 & 359.4 & 338.6 & 320.0 & 313.6 & 382.0 & 350.4 & 322.9 & 315.8 \\
\hline
\end{tabular}

When the flow status was changed from the laminar flow to turbulence flow, the convective heat transfer was increased significantly. Therefore, the peak temperature falls rapidly until the coolant flow rate at the inlet reaches $1.0 \mathrm{~m} / \mathrm{s}$. The falling slope of the peak temperature becomes less steep after the inlet flow rate reaches $1 \mathrm{~m} / \mathrm{s}$. This means that the total heat dissipation does not increase as much as the heat transfer coefficient within the coolant channel does, because the temperature gap between coolant and T/R module decreases. As a result, the heat transfer coefficient within the coolant channel increases with the coolant flow rate while the peak temperature converges toward a specific value. Hence, the cooling performance of the AESA radar coolant channel cannot be improved by raising the coolant flow rate at the inlet alone. Moreover, under the condition of limited volume when installing the coolant circulator on a destroyer or a fighter, it is necessary to set the flow condition leading to the maximum performance with the minimum flow rate as the operation condition. Based on the results of this study, the number of coolant channels should be determined in the inlet Reynolds number range from 1000 to 2000.

The increase in the number of $\mathrm{T} / \mathrm{R}$ modules in the array was found to be associated with the increase in the peak temperature. When one T/R module is installed, heat generated inside the module is transferred solely to the cooling plate and coolant, and the surface exposed to ambient air has a low Ra value. In this case, because heat is released outside only at the level of thermal conductivity of air, the wall can be considered to be almost insulating. In the case of eight or sixteen $\mathrm{T} / \mathrm{R}$ modules in an array, the contacts between $T / R$ module walls lead to a temperature rise as the heat values of the front part $\mathrm{T} / \mathrm{R}$ modules are transferred to the back part. As a result, the temperature increases with the number of $\mathrm{T} / \mathrm{R}$ modules.

Figure 8 illustrates the temperature distribution of each T/R device. Among T/R devices, DRA shows the highest value, followed by HPA and LAN2. The temperature of each device varies depending on the heat value and contact surface. The heat value per unit area was the highest in HPA $\left(470,000 \mathrm{~W} / \mathrm{m}^{2}\right)$. However, the temperature of HPA was lower than that of DRA, because the cooling performance was increased by stacking $\mathrm{CuW}$ between the HPA device and housing to release heat to the outside. On the other hand, because the DRA and LAN2 are placed on the PCB, their temperature is higher because of the insulating effect of the PCB. A comparison between LAN1 and LAN2 reveals a temperature difference of approximately $2^{\circ}$. This shows how the heat dissipation performance differs depending on whether the device is installed directly on the aluminum housing or on the PCB. Thus, to minimize the peak temperature of each device, the installation mode considering heat dissipation was found to be important, in addition to the operating condition of the external coolant channel.

Within a module, the highest temperature area is shown around DRA and HPA in Channel 3, which is disadvantaged in heat release to the outside. This area is characterized by a higher temperature profile compared with other areas owing to the HPA with a high heat value and the connected array of PCB-insulated DRA. If the heat value of each device or heat dissipation layer is not separately configured, the device-to-device distance or installation position may be adjusted to minimize the peak temperature. 


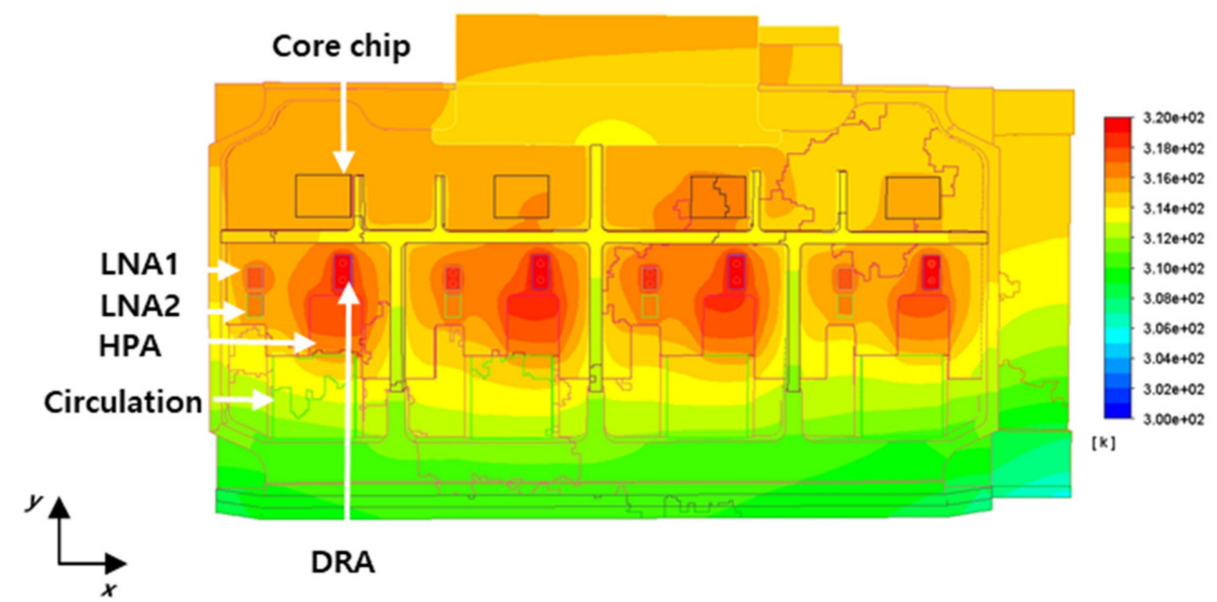

Figure 8. Temperature distribution inside the $\mathrm{T} / \mathrm{R}$ module.

Figure 9 shows the temperature distribution in the cross section of the T/R module. As the coolant flow rate increases, the temperature decreases in the same trend as in Figure 5. It is possible to confirm that the heat transfers from the T/R devices to the coolant in the temperature distribution of the cross section. The temperature distribution inside the coolant rises largely near the aluminum coolant channel, but the temperature of the cooling water in the center of the channel remains unchanged. As the flow rate increases, the temperature near the wall of the coolant channel decreases, and it is because the cooling capacity remains even if the $T / R$ module is additionally arranged.

Figure 10 plots the surface temperature profile on the cooling plate in the cooling flow direction (x-axis direction) of the coolant of a T/R module array at a flow of 0.5 and $1 \mathrm{~m} / \mathrm{s}$. Because the cooling plate temperature increases as the heat is transferred from the $T / R$, it is used as the indicator of cooling performance according to the number of $T / R$ modules in the array.

As shown in the graph, if the T/R modules are connected in series, the cooling plate temperature in the case of laminar flow increases continuously in the direction of the coolant flow. This is because, as the coolant flows in laminar flow, the convective heat transfer coefficient is low, and thus the amount of heat from the T/R device cannot be properly cooled.

On the other hand, when the coolant flow is turbulent, the temperature converges. This is because the coolant cools the heat generated from the T/R module as the convective heat transfer coefficient increases due to turbulent flow. In a series connection of two or more $\mathrm{T} / \mathrm{R}$ modules, the first module undergoes an increase in the cooling plate temperature of $4{ }^{\circ} \mathrm{C}$ at the rate $0.66^{\circ} \mathrm{C} / \mathrm{cm}$, which decreases to $1.0^{\circ} \mathrm{C}\left(0.17^{\circ} \mathrm{C} / \mathrm{cm}\right)$ in the second module, and further to $0.4{ }^{\circ} \mathrm{C}\left(0.06^{\circ} \mathrm{C} / \mathrm{cm}\right)$ in the third module. In the back two modules, the cooling plate temperature tends to increase less on account of the heat dissipation effect on the module surface exposed to ambient air.

The declining rate of the temperature increase on the cooling plate is attributable to the declining cooling capacity of the $T / R$ module, because the temperature of the coolant increases downstream. As shown in Table 6, when the coolant flow rate is low $(\mathrm{V}=0.125 \mathrm{~m} / \mathrm{s})$, temperature can change by more than $50^{\circ} \mathrm{C}$ according to the number of module arrays owing to the limit to the cooling performance by the coolant heat capacity. When there are four $\mathrm{T} / \mathrm{R}$ module connections, it is managed below $70^{\circ} \mathrm{C}$ until $\mathrm{Re}=1111$ of the coolant. However, when the number of $\mathrm{T} / \mathrm{R}$ modules increases to eight, the temperature rises near $80^{\circ} \mathrm{C}$ and approaches the allowable AESA radar temperature. 

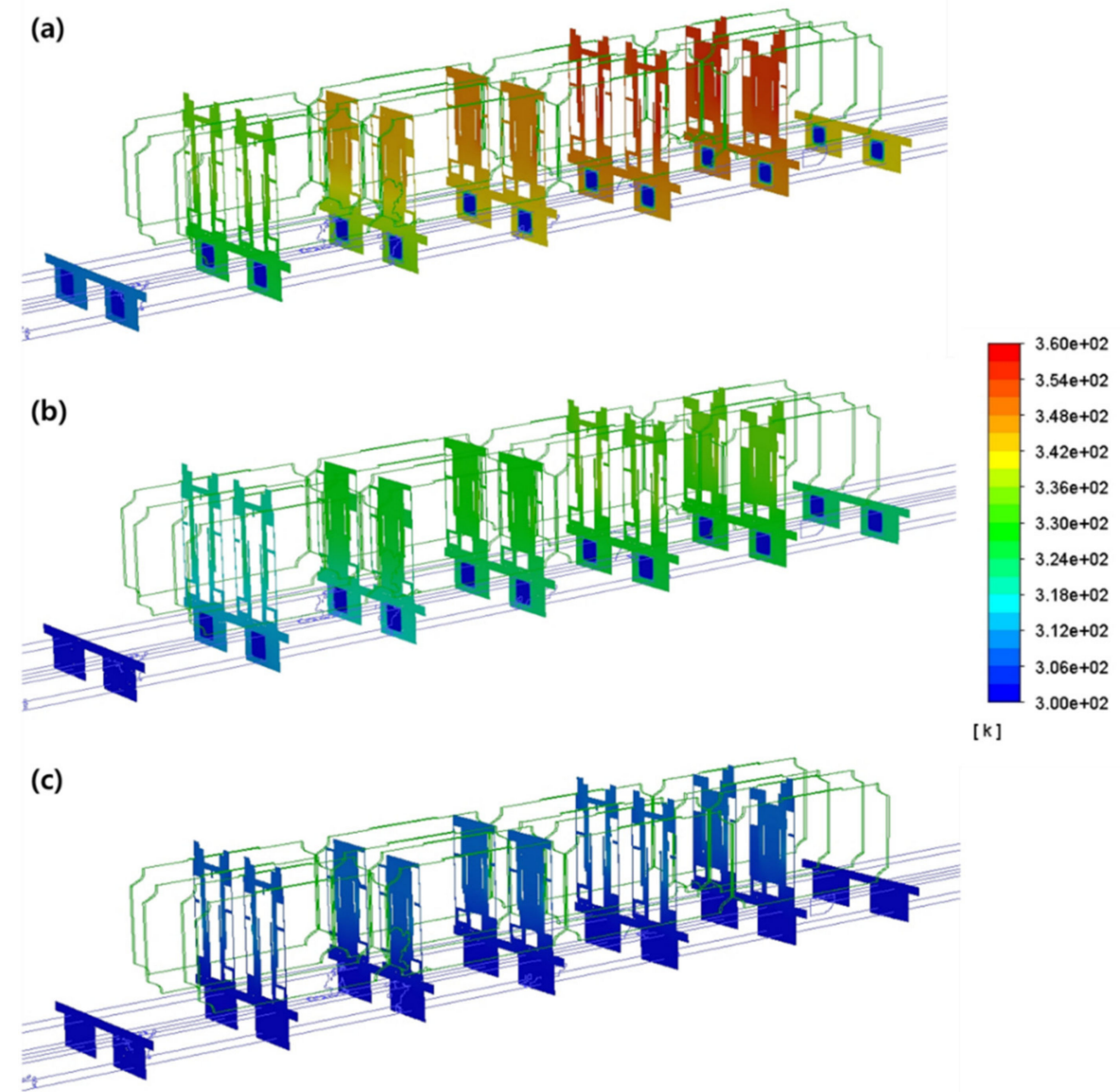

Figure 9. Temperature distribution in the cross section of $T / R$ module: (a) $V=0.125 \mathrm{~m} / \mathrm{s}$, (b) $\mathrm{V}=0.5 \mathrm{~m} / \mathrm{s},(\mathbf{c}) \mathrm{V}=1.0 \mathrm{~m} / \mathrm{s}$.

(a)

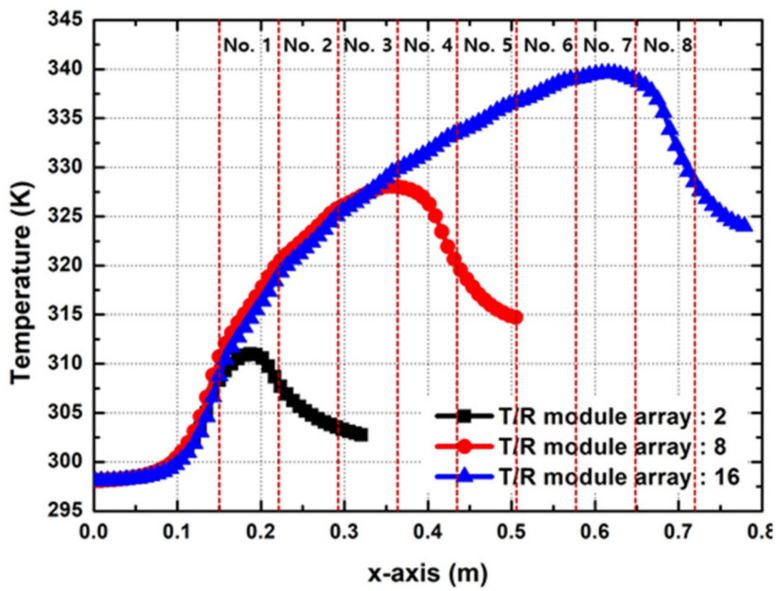

(b)

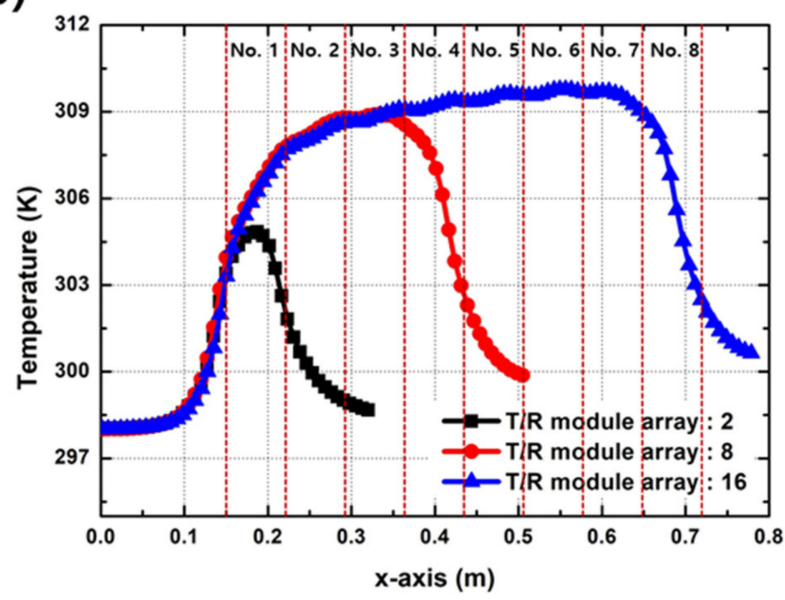

Figure 10. Surface temperature profile on the cooling plate in the flow direction (x-axis direction): $(\mathbf{a}) \mathrm{V}=0.5 \mathrm{~m} / \mathrm{s}(\operatorname{Re}=1111)$, (b) $\mathrm{V}=1.0 \mathrm{~m} / \mathrm{s}(\operatorname{Re}=2222)$.

On the other hand, when $\operatorname{Re}=2222$ of the coolant, the cooling performance is sufficient, and it can be confirmed that the temperature remains constant even when the number of $\mathrm{T} / \mathrm{R}$ modules increases. Therefore, when up to four $\mathrm{T} / \mathrm{R}$ modules are connected in series, $\operatorname{Re}=1000 \sim 1500$ of cooling water can cool the AESA radar within the target temperature sufficiently. If the number of $T / R$ modules is more than four, the cooling water must be in a turbulent state for sufficient cooling. 


\section{Conclusions}

In this study, computational analysis was performed to determine the temperature profile resulting from the heat generation and cooling of an eight-channel $\mathrm{T} / \mathrm{R}$ module array to be installed in an AESA radar. By modifying the coolant flow rate and the number of $\mathrm{T} / \mathrm{R}$ modules, various boundary conditions for heat generation and cooling were examined to establish basic data for the optimal design of the cooling system. According to the results, an increase in the coolant flow rate could improve cooling performance, thereby decreasing the $T / R$ module temperature. The increase in the $T / R$ module temperature was found to slow down when the flow rate reached a specific level. When the number of modules in the $\mathrm{T} / \mathrm{R}$ module array increased, the temperature increased because the internal heat could not be released to the outside. In addition, insufficient coolant supply substantially reduced the cooling performance of the coolant because its heat capacity was saturated as the number of modules increased. When there are four or less T/R modules, cooling is possible within the target temperature of the AESA radar, as $\mathrm{Re}=1000$ or more. However, when four or more $\mathrm{T} / \mathrm{R}$ modules are connected in series, sufficient cooling performance can be secured only when coolant is supplied through turbulent flow with a Reynolds number of 2000 or higher. This study established basic data on coolant operating conditions and array for designing the cooling system for an AESA radar of $1000 \mathrm{Ch}$ or more.

Author Contributions: Conceptualization and Funding acquisition, D.-J.S., S.-H.K. and S.-H.Y.; Investigation and Writing - original draft, J.S.P. All authors have read and agreed to the published version of the manuscript.

Funding: This research was supported by LIG Nex1 Co. and Basic Science Research Program through the National Research Foundation of Korea (NRF) funded by the Ministry of Education (2019R1F1A1059573).

Conflicts of Interest: The authors declare no conflict of interest.

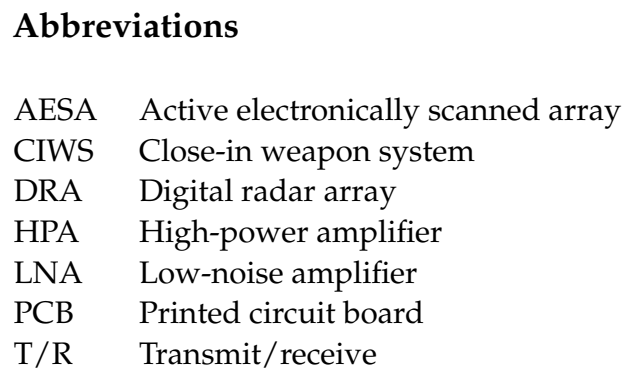

\section{Nomenclature}

g Gravitational acceleration $\left(\mathrm{m} / \mathrm{s}^{2}\right)$

L T/R device length (m)

$\mathrm{Nu}$ Nusselt number

Pr Prandtl number

Q Rate of heat $(\mathrm{W})$

$\dot{Q} \quad$ Heat flux $\left(\mathrm{W} / \mathrm{m}^{2}\right)$

$\mathrm{Ra}$ Rayleigh number

Re Reynolds number

$T_{S} \quad$ Surface temperature of $\mathrm{T} / \mathrm{R}$ device $\left({ }^{\circ} \mathrm{C}\right)$

$T_{\infty} \quad$ Ambient temperature $\left({ }^{\circ} \mathrm{C}\right)$

$V \quad$ Coolant flow rate $(\mathrm{kg} / \mathrm{s})$

$\mathrm{x} \quad \mathrm{x}$-direction

y $\quad \mathrm{y}$-direction

$\mathrm{z} \quad \mathrm{z}$-direction

$\beta \quad$ Air thermal expansion coefficient (1/deg)

$v \quad$ Kinematic viscosity coefficient $\left(\mathrm{m}^{2} / \mathrm{s}\right)$ 


\section{References}

1. Kim, D.Y.; Chong, M.K.; Kim, S.K.; Chon, S.M.; Na, H.G.; Baik, S.H.; Ahn, C.S.; Kim, S.J. T/R Module Development for X-Band Active Phased-Array Radar. J. Korean Inst. Electromagn. Eng. Sci. 2009, 20, 1243-1251. [CrossRef]

2. Moore, D.S. Review of the state of the art of UK AESA technology and the future challenges faced. In Proceedings of the IEEE Radar Conference, Rome, Italy, 26-30 May 2008; pp. 1-6. [CrossRef]

3. Milin, J.; Moore, S.; Bürger, W.; Triboulloy, P.; Royden, M.; Gerster, J. AMSAR-A European success story in AESA radar. In Proceedings of the International Radar Conference "Surveillance for a Safer World" (RADAR 2009), Bordeaux, France, 12-16 October 2009; pp. 1-6.

4. Wang, Y.; Wang, C.; Lian, P.; Xue, S.; Liu, J.; Gao, W.; Shi, Y.; Wang, Z.; Yu, K.; Peng, X.; et al. Effect of Temperature on Electromagnetic Performance of Active Phased Array Antenna. Electronics 2020, 9, 1211. [CrossRef]

5. Brookner, E. Active electronically scanned array (AESA) system noise temperature. In Proceedings of the 2013 IEEE International Symposium on Phased Array Systems and Technology, Waltham, MA, USA, 15-18 October 2013; pp. $760-767$.

6. Rummel, K.A.; Schaefer, G.; Chen, K.W.; Allen, B.H.; Weissman, D.J. Remote Cooling of a Phased Array Antenna. U.S. Patent Application No. 11,865,475, 4 February 2009.

7. Brookner, E.; Howell, J.M. Right way to calculate reflector and active-phased-array antenna system noise temperature taking into account antenna mismatch. In Proceedings of the IEEE International Symposium on Phased Array Systems and Technology, Boston, MA, USA, 14-17 October 2003; pp. 130-135.

8. Przemysław, S.; Sławomir, P. A review of the capabilities of high heat flux removal by porous materials, microchannels and spray cooling techniques. Appl. Therm. Eng. 2016, 104, 636-646.

9. Agrawa, A.K.; Kopp, B.A.; Luesse, M.H.; O’Haver, K.W. Active Phased Array Antenna Development for Modern Shipboard Radar System. Johns Hopkins APL Tech. Dig. 2001, 22, 600-613.

10. Josefsson, L.; Erhage, L.; Emanuelson, T. An AESA development model for next generation fighter aircraft radar. In Proceedings of the International Symposium on Phased Array Systems and Technology, Boston, MA, USA, 15-18 October 1996; pp. 454-457. [CrossRef]

11. Bergman, T.L.; Incropera, F.P.; DeWitt, D.P.; Lavine, A.S. Fundamentals of Heat and Mass Transfer; John Wiley \& Sons: New York, NY, USA, 2002. 